\title{
Anterior sacral Meningocele Associated with Tethered Cord Syndrome Presenting with Constipation: US, CT, MRI and X-Ray Findings
}

\author{
Gokhan Soker ${ }^{1}$, Eda Soker ${ }^{2}$, Bozkurt Gulek¹, Tugba Tumer ${ }^{3}$, Omer Kaya1, \\ Muhammet Arslan', Ayse Yildirim Celikdemir ${ }^{1}$, Cengiz Yılmaz ${ }^{1}$ \\ ${ }^{1}$ Department of Radiology, Numune Teaching and Research Hospital, Adana, Turkey \\ ${ }^{2}$ Department of Physical Therapy and Rehabilitation, Numune Teaching and Research Hospital, Adana, Turkey \\ ${ }^{3}$ Department of Radiology, Mersin University Faculty of Medicine, Mersin, Turkey \\ Email: gsoker@hotmail.com
}

Received 14 May 2015; accepted 20 June 2015; published 23 June 2015

Copyright (C) 2015 by authors and Scientific Research Publishing Inc.

This work is licensed under the Creative Commons Attribution International License (CC BY). http://creativecommons.org/licenses/by/4.0/

(c) (i) Open Access

\begin{abstract}
Anterior sacral meningocele is characterized by the herniation of the thecal sac into the retroperitoneal space. A 33-year-old man was referred to our hospital with the complaints of a longlasting constipation and nonspecific lower abdominal pain. At ultrasound, a cystic mass was detected at the presacral space. Computed Tomography revealed a defect at the anterior aspect of the sacrum, together with a presacral cystic mass which showed a connection with the dural sac. At Magnetic Resonance Imaging, it was demonstrated that the cystic mass made an impression on the rectum, and did not possess any solid components. An anteroposterior pelvis radiogram demonstrated a sacral deformity and the scimitar sign. Upon these imaging findings, the patient got the diagnosis of an anterior sacral meningocele. The possibility of an anterior sacral meningocele must always be kept in mind in the differential diagnosis of a pelvic cystic mass.
\end{abstract}

\section{Keywords}

Anterior sacral Meningocele, Pelvic Cyst, Tethered Cord, MRI, Ultrasonography

\section{Introduction}

Anterior sacral meningocele (ASM) is characterized by the herniation of the thecal sac into the presacral retro-

How to cite this paper: Soker, G., Soker, E., Gulek, B., Tumer, T., Kaya, O., Arslan, M., Celikdemir, A.Y. and Yılmaz, C. (2015) Anterior sacral Meningocele Associated with Tethered Cord Syndrome Presenting with Constipation: US, CT, MRI and X-Ray Findings. Open Journal of Radiology, 5, 111-116. http://dx.doi.org/10.4236/ojrad.2015.52017 
peritoneal space [1]-[3]. It is a rare entity and constitutes a very small portion of the cystic masses of the pelvis. It makes up only $5 \%$ of all retrorectal masses [4]-[6]. The prevalence of ASM is 1 in 1000 live births [7]. The disease is usually asymptomatic, but may turn symptomatic when the size of the mass starts to increase. In such occasions, urinary problems, dysmenorrhea, constipation, and even an ileus may develop [8]-[10]. It may be mistaken for other causes of a pelvic cystic mass, especially when the neck connecting the cyst with the thecal sac is narrow. Due to the high complication risk of needle aspiration, pelvic cystic mass cases must be thoroughly examined and the possibility of an ASM must always be kept in mind as a vital differential diagnosis.

\section{Case Report}

A 33-year-old man applied to our hospital with the complaints of a long-lasting constipation and a nonspecific lower abdominal pain. His physicals did not reveal any abnormalities, and his routine laboratory work-up was within normal limits. The patient was examined by ultrasonography (US) (DC-7, Mindray Ltd., China). US examination disclosed a cystic mass of a size of $6.0 \times 7.5 \times 7.5 \mathrm{~cm}$, at the posterior aspect of the bladder. The lesion was extending to the presacral space posteriorly, and had a bilobulated appearance at this site (Figure 1). No solid components could be visualized in the cyst. Although an ASM was among the differential list, a Computed Tomography (CT) examination was planned because other differential diagnostic possibilities could not yet be ruled out at this level of the evaluation. CT examination was performed with a 16-row multidetector scanner (Somatom Sensation 16, Siemens AG, Germany). CT revealed a bony defect at the anterior part of the sacral bone, together with a presacral cystic mass which demonstrated a connection with the dural sac (Figure 2). Magnetic Resonance Imaging (MRI) examination was done in a 1.5 Tesla (T) MRI system (Magnetom, Siemens AG, Germany). At MRI, a cystic mass which was hypointense on T1-weighted (T1W), and hyperintense on $\mathrm{T} 2$-weighted (T2W) sequences at the presacral space was demonstrated. Sagittal images clearly demonstrated that the cyst was in connection with the dural sac through the bony defect at the sacrum (Figure 3). It was also noted that the spinal cord was low-lying and ending at the level of the lower plate of the L5 vertebral body (Figure 4). After intravenous contrast injection, no solid or neural components could be visualized in the mass. The axial T1W images showed that the mass was exerting pressure on the rectum (Figure 5). An anteroposterior (AP) pelvis radiogram demonstrated a sacral deformity and the scimitar sign (Figure 6). Upon these imaging findings, the patient got the diagnosis of an anterior sacral meningocele. The neurologic examination of the patient revealed no deficits. The patient was provided satisfying information concerning the necessity of surgery and follow-up. But, rejecting the idea of surgery, the patient, who demonstrated no clinical symptoms other than constipation, was put into a follow-up program. The patient was followed by US for a year, and no progression in the lesion size was detected during this time period.

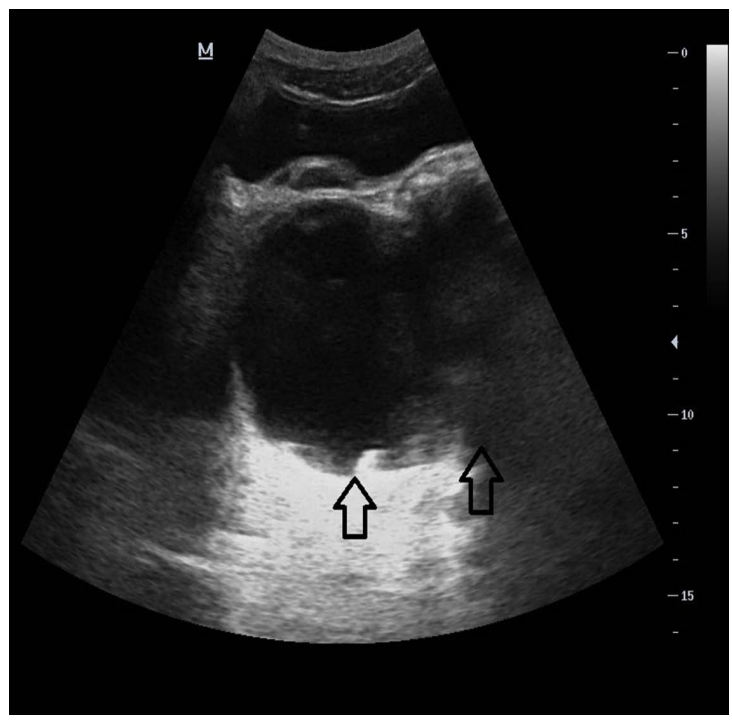

Figure 1. A bilobulated anechoic cystic mass is present at the posterior aspect of the bladder (arrows). 


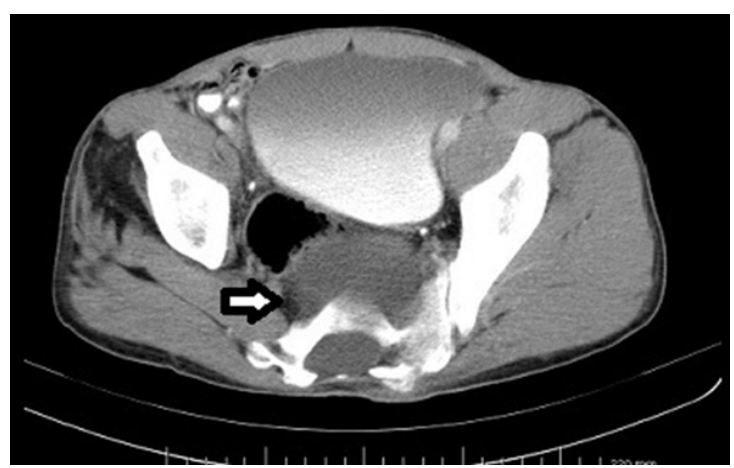

Figure 2. At axial CT, hypodense pelvic mass lesion is seen extending to the retroperitoneal space through a bony defect at the anterior wall of the sacrum (arrow).

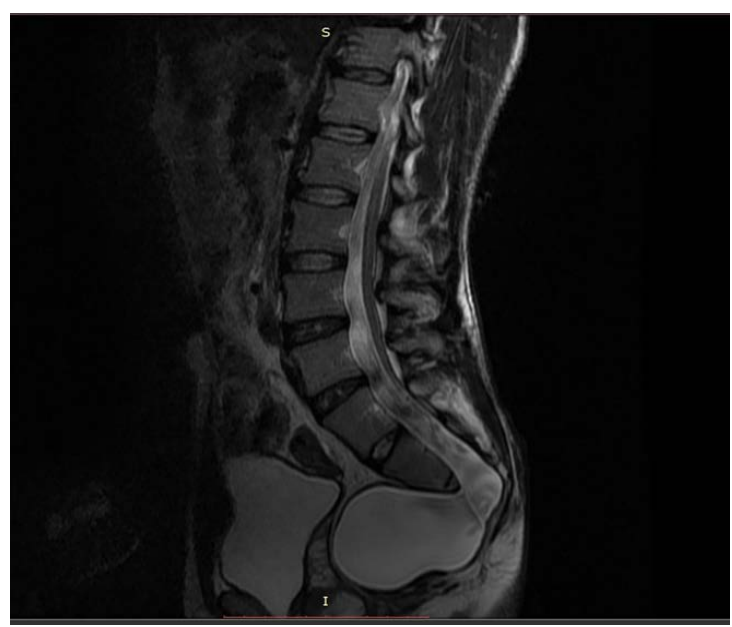

Figure 3. At sagittal T2 weighted MRI sequence the continuation of the cystic mass with the thecal sac is clearly visible.

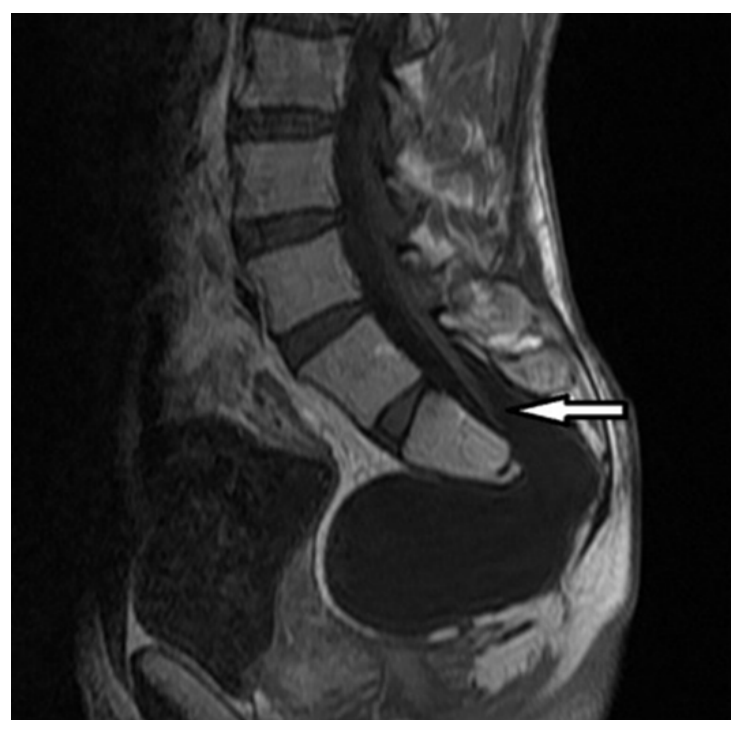

Figure 4. Sagittal T1W sequence demonstrates the lowending spinal cord at the sacral level (arrow). 


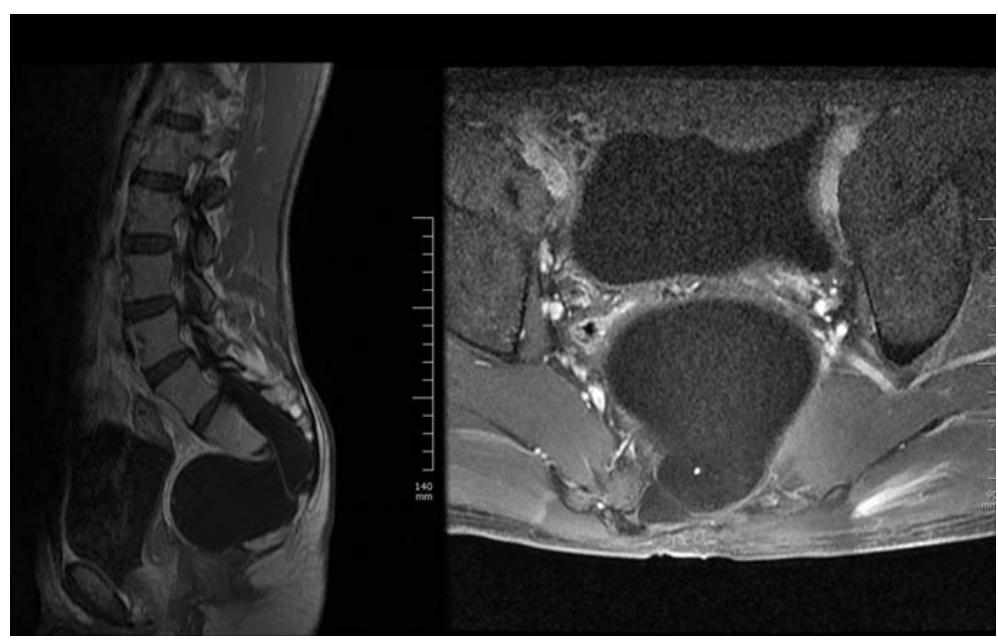

Figure 5. These sagittal and axial MRI views demonstrate the pelvic cystic mass with no enhancing solid components in the mass. Pay attention the impression exerted on the rectum by the cystic mass (arrow).

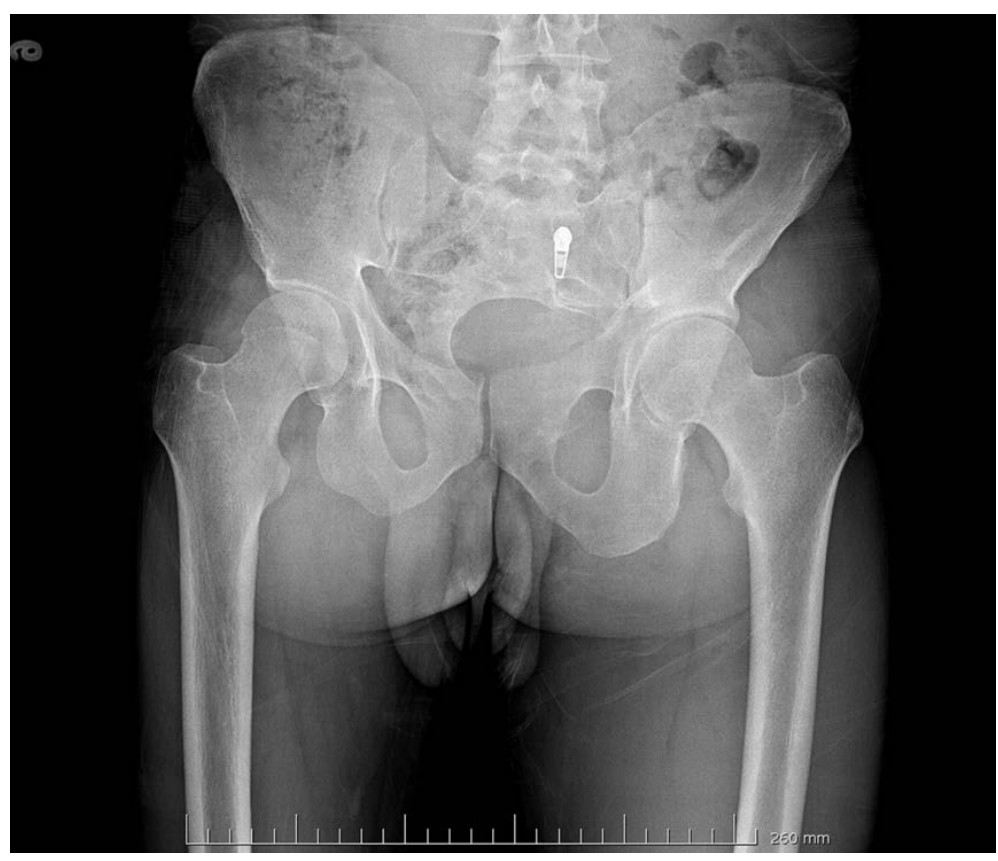

Figure 6. AP-pelvis radiogram demonstrating sacral bone at the left lateral aspect of the sacrum (scimitar sign)

\section{Discussion}

ASM is characterized by the herniation of the thecal sac into the presacral retroperitoneal space through the sacral foramen or a defect at the sacral bone [1] [2]. The disease is usually asymptomatic, but may turn symptomatic when the size of the mass starts to increase. In such occasions, urinary problems, dysmenorrhea, constipation as in our case, and even an ileus, may develop. Patients may demonstrate nonspecific symptoms [8]-[10]. In advanced stages of the disease when the size of the cystic mass reaches critical levels and the mass starts exerting serious pressure on the neighboring tissues, symptoms arise such as sciatalgia, decreased rectum and detrussor tonus, sensory loss at the lower sacral dermatomes, and paresthesia [3] [8].

Conventional radiography, US, CT and MRI all play important roles in the diagnosis of ASM. Radiologic imaging findings include a bony defect at the anterior wall of the sacrum, enlarged foramens, and a cystic mass 
localized at the pelvis. The relation and continuation of the pelvic cyst and the dural sac must be demonstrated in order to reach a definitive diagnosis.

The AP pelvis radiogram may demonstrate the sacral bony defect clearly. This defect may present in various forms in a wide spectrum of appearances, from an enlarged sacral foramen to a complete sacral agenesis. The unilateral sacral agenesis, which is a unilateral concave defect, is known as the scimitar sign [5] [11]. The scimitar sign is seen in $50 \%$ of the patients and is known to be a pathognomonic finding of ASM [12] [13]. Our patient, too, demonstrated the scimitar sign.

The pelvic cystic mass is easily demonstrated at US. But in order to make a definitive diagnosis, the relation of the mass with the dural sac must be disclosed well. Especially those cysts with narrow necks may be mistaken for an ovarian cyst or a full bladder [2] [4] [14]. It is very important to make a definitive differential diagnosis of an ASM in pelvic cystic masses. This is because in patients who suffer from this disease and who lack this differential evaluation, a surgical or an interventional approach may lead to very serious complications such as a meningitis or a sudden fall in intracranial pressure [6] [9] [15]. US is also very valuable in the follow-up of patients who are not scheduled for surgery [4]. CT may demonstrate the bony abnormalities at the anterior sacral wall in a much better fashion than any other imaging modality. Administration of intrathecal contrast media may disclose the relation of the dural sac and the presacral cyst perfectly. It may also help detect any solid components of the cystic mass [4]. But since CT myelography is an invasive procedure and utilizes ionizing radiation, it must be saved for those cases with cysts with a narrow neck which present difficulties in the detection of the relation of the cyst and the thecal sac [12].

MRI is superior to other imaging modalities in the diagnosis of ASM, due its multiplanar imaging capability. Uncomplicated cysts which possess no solid components appear hypointens on $\mathrm{T} 1 \mathrm{~W}$, and hyperintense on $\mathrm{T} 2 \mathrm{~W}$, sequences. Utilization of contrast media also helps in the demonstration of associating pathological conditions such as a lipoma or a dermoid tumor [11]. MRI may detect the neural components which may be present in the cyst [16] [17]. It has been reported that the spinal cord and the caudaequina are normal in ASM in most cases. But in rare cases as ours, a tethered cord may be present. The level of the conusmedullaris may be clearly depicted on the sagittal MRI views [14] [18] [19]. MRI also makes possible the demonstration of the cyst in three planes, its relations with the neighboring structures, and the continuation of the cyst with the thecal sac without the administration of contrast media [4].

Since ASM does not regress, the symptomatic ASM patient must be treated surgically in order to provide comfort and safety [4]. The purpose of surgery is to terminate the connection between the dural sac and ASM [12]. Asymptomatic patients may be followed up by US. The surgical option must be kept in mind for those patients whose cysts demonstrate an increase in size [4].

ASM may be mistaken for a tail gut duplication cyst, a presacralneurenteric cyst, a sacrococcygealteratoma, a hydatid cyst, or an ovarian cyst [5] [20] [21]. The demonstration of the continuation of the presacral cyst with the thecal sac provides this differentiation.

Before you begin to format your paper, first write and save the content as a separate text file. Keep your text and graphic files separate until after the text has been formatted and styled. Do not use hard tabs, and limit use of hard returns to only one return at the end of a paragraph. Do not add any kind of pagination anywhere in the paper. Do not number text heads - the template will do that for you.

Finally, complete content and organizational editing before formatting. Please take note of the following items when proofreading spelling and grammar:

\section{Conclusion}

ASM is a rare cause of the cystic lesions of the pelvis. It may be mistaken for other causes of a pelvic cystic mass, especially when the neck connecting the cyst with the thecal sac is narrow. Due to the high complication risk of needle aspiration, pelvic cystic mass cases must be thoroughly examined and the possibility of an ASM must always be kept in mind as a vital differential diagnosis. MRI is a very effective and safe modality in the demonstration of all of the findings of ASM. Those cases which are not planned to have surgery may be followed up by US.

\section{References}

[1] Versteegh, H.P., Feitz, W.F., vanLindert, E.J., Marcelis, C. and de Blaauw, I. (2013) “This Bicycle Gives Me a 
Headache", a Congenital Anomaly. BMC Research Notes, 14, 412. http://dx.doi.org/10.1186/1756-0500-6-412

[2] McGregor, C., Katz, S. and Harpham, M. (2013) Management of a Parturient with an Anterior Sacral Meningocele. International Journal of Obstetric Anesthesia, 22, 64-67. http://dx.doi.org/10.1016/j.ijoa.2012.08.007

[3] Erdogmus, B., Yazici, B., Ozdere, B.A. and Safak, A.A. (2006) Anterior Sacral Meningocele Simulating Ovarian Cyst. Journal of Clinical Ultrasound, 34, 244-246. http://dx.doi.org/10.1002/jcu.20198

[4] Polat, A.V., Belet, U., Aydin, R. and Katranci, S. (2013) Anterior Sacral Meningocele Mimicking Ovarian Cyst: A Case Report. Medical Ultrasonography, 15, 67-70. http://dx.doi.org/10.11152/mu.2013.2066.151.avplasm2

[5] Mohta, A., Das, S. and Jindal, R. (2011) Anterior Sacral Meningocele Presenting as Constipation. Journal of Pediatric Neurosciences, 6, 40-43.

[6] Liu, L., Li, J., Huang, S. and You, C. (2011) Adult Anterior Sacral Meningoceles Misdiagnosed as Pelvic Cysts. British Journal of Neurosurgery, 25, 532-533. http://dx.doi.org/10.3109/02688697.2010.546901

[7] Basak, M., Ozkurt, H., Yildirim, H., et al. (1999) Case Report: A True Anterior Thoracic Meningomyelocele Presenting with Respiratory Symptoms. Diagn Intervent Radiol, 5, 489.

[8] Hemama, M., Lasseini, A., Rifi, L., Boutarbouch, M., Derraz, S., Ouahabi, A.E. and Khamlichi, A.E. (2011) A Sacral Hydatid Cyst Mimicking an Anterior Sacral Meningocele. Journal of Neurosurgery: Pediatrics, 8, 526-529. http://dx.doi.org/10.3171/2011.8.PEDS10555

[9] Aydoseli, A., Akcakaya, M.O., Aras, Y., Dolas, I. and Yanar, H.A. (2013) Anterior Sacral Meningocele in a Patient with Currarino Syndrome as a Cause of İleus. British Journal of Neurosurgery, 27, 833-835. http://dx.doi.org/10.3109/02688697.2013.785476

[10] Lefere, M., Verleyen, N., Feys, H. and Somers, J.F. (2009) Anterior Sacral Meningocoele Presenting as Acute Urinary Retention. A Case Report. Acta Orthop Belg, 75, 855-857.

[11] Venyo, A., Shah, S. and Desai, N. (2011) An Unusual Presentation of Anterior Sacral Meningocele: A Case Report and a Review of the Literature. Webmed Central Urology, 2, Article ID: WMC002308.

[12] Martin, B. and de Latour, F.B. (1988) MR Imaging of Anterior Sacral Meningocele. Journal of Computer Assisted Tomography, 12, 166-167. http://dx.doi.org/10.1097/00004728-198801000-00038

[13] Kovalcik, P.J. and Burke, J.B. (1988) Anterior Sacral Meningocele and the Scimitar Sign. Report of a Case. Diseases of the Colon \& Rectum, 31, 806-807. http://dx.doi.org/10.1007/BF02560112

[14] Castelli, E., Rosso, R., Leucci, G., Luparello, V., Collura, D., Giacobbe, A. and Muto, G. (2013) Huge Anterior Sacral Meningocele Simulating Bladder Retention. Urology, 81, 9-10. http://dx.doi.org/10.1016/j.urology.2012.11.015

[15] Swamy, S., Edwin, P., Babu, P., Joy, B. and Devi, R. (2003) Anterior Sacral Meningocele-As Part of the Currarino Triad. Indian Journal of Radiology and Imaging, 13, 207-208.

[16] Hara, Y., Shirane, R. and Yoshimoto, T. (1992) Anterior Sacral Meningocele Associated with Tethered Cord Syndrome. No Shinkei Geka, 20, 1217-1221.

[17] North, R.B., Kidd, D.H. and Wang, H. (1990) Occult, Bilateral Anterior Sacral and İntrasacral Meningeal and Perineurial Cysts: Case Report and Review of the Literature. Neurosurgery, 20, 981-986. http://dx.doi.org/10.1097/00006123-199012000-00020

[18] Jeelani, N.O., Jaspan, T. and Punt, J.A.G. (1999) Tethered Cord Syndrome after Myelomeningocoele Repair. British Medical Journal, 318, 516-517. http://dx.doi.org/10.1136/bmj.318.7182.516

[19] Miletic, D., Poljak, I., Eskinja, N., Valkovic, P., Sestan, B. and Troselj-Vukic, B. (2008) Giant Anterior Sacral Meningocele Presenting as Bacterial Meningitis in a Previously Healthy Adult. Orthopedics, 31, 182. http://dx.doi.org/10.3928/01477447-20080201-21

[20] Agrawal, A., Banode, P.J., Srivastava, S. and Sunkara, A. (2009) Osteoid Osteoma of the Femur: Masquerading the Tethered Cord Syndrome. Journal of Radiology Case Reports, 3, 5-8. http://dx.doi.org/10.3941/jrcr.v3i4.135

[21] Beyazal, M. (2013) An Asymptomatic Large Anterior Sacral Meningocele in a Patient with a History of Gestation: Acase Report with Radiological Findings. Case Reports in Radiology, 2013, Article ID: 842620. http://dx.doi.org/10.1155/2013/842620 